\title{
Milli Görüş Partilerinin Eğitim ve Kültür Programlarının Değerlendirilmesi
}

\author{
DOI: 10.26466/opus. 812741 \\ * \\ Yusuf Yalanız - Beyhan Zabun ** \\ *Koordinatör, Ekonomik ve Sosyal Araştırmalar Merkezi \\ E-Posta: yusufyalaniz@gmail.com \\ ORCID: $\quad \underline{0000-0003-4330-4103}$ \\ **Prof. Dr., Gazi Üniversitesi \\ E-Posta: bzabun@gazi.edu.tr \\ ORCID: 0000-0001-8974-9103
}

\section{Öz}

Bu makalenin amacl, Türkiye siyaset tarihinde otantik / özgün bir siyaset kültürüne sahip olan Milli Görüş partilerinin eğitim ve kültür programlarm siyaset sosyolojisi ve siyaset biliminin temel yaklaşımları çerçevesinde değerlendirmektir. Araştırma, literatür taramasına dayalı tarihsel yöntem ile ele alınmıştır. Bu yöntem ile bir süreç dâhilindeki çeşitli dönemler, kendi konjonktürleri dâhilinde incelenmiş ve kavramsal analizlerle değerlendirilmiştir. Buna göre araştırma, nitel verilere dayalı değerlendirmelerin bir araya getirilmesiyle oluşturulmuştur. Çalışma, Milli Görüş partileri olarak nitelendirilen Milli Nizam Partisi, Milli Selamet Partisi, Refah Partisi, Fazilet Partisi ve Saadet Partisi kapsamunda kronolojik bir çerçeve ile belirtilmiştir. Daha sonra araştırma analizleri, bu kapsamda belirtilen partilerin parti programı, seçim beyannamesi, koalisyon protokolü, hükümet programı ve politikaları sınırllıklarıyla değerlendirilmiştir. Belirtilen amaç doğrultusunda partiler, dönemsel farklılıkların belirlenmesi ve bütünlüğ̈̈ sağlaması açısından bölümlere ayrılmış ve her bir bölüm kendi içinde de analiz edilmiştir. Sonuç olarak geleneksel bir siyasi kültüre sahip olmasına rağmen Milli Görüş partilerinde eğitim ve kültür alanlarıyla ilgili olarak form, üslup ve içerik bakımından çeşitli değişimlerin olduğu tespit edilmiştir.

Anahtar Kelimeler: Eğitim, kültür, milli görüş, siyasal toplumsallaşma, siyaset 


\title{
Analysis of the Education and Culture Programs of Milli Gorus Parties
}

\begin{abstract}
The aim of this article is to observe the education and culture programs of Milli Gorus Parties, having an authentic and characteristic political culture in the history of Turkish politics, within the framework of the basic approaches of political sociology and political science. This research is approached with historical method based on literature review. With this method research, various periods in a process are observed in their own conjectures and evaluated by conceptual analysis. According to this, the research is constituted by gathering the analysis based on qualitative data. The research is stated with a chronological frame within the scope of Milli Gorus Parties, such as Milli Nizam Party, Milli Selamet Party, Refah Party, Fazilet Party and Saadet Party. And then the research analysis is evaluated by the borders of these stated parties' party programs, declarations of election, coalition protocols, government programs and policies. In the direction of determined aim the parties are divided into periods to state the periodical differences and to get the coherence and each period is analysed in itself as well. In conclusion, although parties have a traditional political culture, it is observed that Milli Gorus parties have various changes in their education and culture programs by form, style and content.
\end{abstract}

Keywords: Culture, education, milli gorus, political socialization, politics 


\section{Giriş}

Türkiye'de çok partili siyasal hayata geçilmesi ve 1950 'den sonra yaşanan sosyolojik değişimler siyasa algısının değişmesine ve beraberinde toplumsal yapının hareketlenmesine sebep olmuştur. Çok partili siyasal sistemin belirginleşmesi, toplumun siyasette etkililiğinin artması ve 1960 ihtilalinden sonra hazırlanan anayasa yeni bir sivil toplum anlayışı geliştirmiştir.

Milli Görüş Hareketi özellikle bu sivil hareketlilik ve dini-siyasi anlayışın değişmesi üzerine 1969 yılında "Bağımsızlar Hareketi" ile Türkiye siyaset tarihinde yerini almıştır. Daha sonra Milli Görüş partileri kendi serencamı içinde üç defa koalisyon ortağı olmuş ve bir defa da hükümet kurma görevi üstlenmiştir. Her ne kadar Türkiye siyasal hayatında koalisyon partisi olarak uzun süre iktidarda kalmamış olsa da Milli Görüş partilerinin siyasete getirdiği anlayış, toplumda ve siyasette özgün bir karşllık bulmuştur.

Hareketin liderli olan Prof. Dr. Necmettin Erbakan ise nevi şahsına münhasır karakteri ve siyaset tarzı ile Türkiye siyasetine farklı bir yön kazandırmıştır. Erbakan'ı hareketin öncülüğüne taşıyan ve siyasette etkili bir aktör olmasını sağlayan unsurların başında ise eğitim seviyesi, İslami geçmişi, akademik ve bürokratik kariyeri, liderlik özellikleri, ülke meselelerini değerlendirmedeki milli tavrı, İslami kolektif tutum ve dünya görüşü gelmektedir (Tekin, 2017, s.240-243).

MNP (Milli Nizam Partisi) parti üst düzey yapılanması modern eğitimli bir kadro görünümüne sahip olmasına rağmen kapatılmıştır. Daha sonra da RP (Refah Partisi) ve FP (Fazilet Partisi) özellikle dini-siyasal anlayış ve laiklik karşıtı eylemlerin odağı olması iddiasıyla Anayasa Mahkemesi tarafından kapatılmıştır. MSP (Milli Selamet Partisi) ise 12 Eylül Askeri İhtilali ile kapatılmış olsa da parti yöneticileri askeri mahkemeler tarafından dini söylemleri ön plana çıkartmaları sebebi ile suçlanmışlardır.

MNP'den Saadet Partisine olan çizgide parti programları, seçim beyannameleri, koalisyon protokolleri, Meclis konuşmaları, basın açılamaları ve diğer parti resmi yayınları incelendiğinde dini üslup, temellendirme ve arka plan açık bir şekilde gözlemlenmektedir. Dolayısıyla farklı alanlarda yapılan "Milli Görüsş" temalı çalışmaların çoğunluğu "din olgusu" ve din-siyaset ilişkisi bağlamlarını konu almıştır. 
Milli Görüş partilerinin eğitim ve kültür programlarının değerlendirildiği bu çalışmada da benzer nitelikler incelenmiştir. Ancak bağlamın ağırlık merkezi, sürekli olarak din-siyaset ilişkisinin angaje edildiği bir mihraklaşmadan ziyade "parti-toplum-siyasal" eksenine tekabül eden daha geniş bir literatüre oturtulmuştur.

\section{Milli Görüş Düşüncesi ve Ortaya Çıkışındaki Siyasi Saikler}

Türkiye siyasi tarihinde Cumhuriyet Dönemi'nin ilk yılları resmi ve ideolojik devlet anlayışının hâkim olduğu tek partili iktidar dönemlerine karşıllık gelmektedir. İdeolojik devlet anlayışına bağlı olarak siyasette ve dini alanda birçok sinırlılıklar oluşturulmuştur. Toprak'a (2000, s. 392) göre her ne kadar cumhuriyet devrimlerinin sert tutumu karşısında dini alan daraltılmış ve dini anlayış geri çekilmiş olsa da bu gerileme ancak 1945 yılına kadar sürebilmiştir.

Türkiye'nin sosyolojik yapısı daha sonra çok partili demokratik hayata geçişi zorunlu kılmıştır. Dolayısıyla 1946 yılında muhalif partilerin kurulmasina izin vermiş ve 7 Ocak 1946 tarihinde DP (Demokrat Parti) resmen kurulmuştur. DP, siyasallaşan toplumsal muhalefetin dilini muhatap almaya başlamış, dini alanın sıkıştı̆̆ toplumsal hoşnutsuzlukları siyasal bir proje haline dönüştürerek iktidara gelmiş ve dini düşüncenin yeniden canlılık kazanmasını sağlamıştır (Bulaç, 2009, s.14).

DP iktidarının dini alana ilişkin icraatlarının başında ezanın Arapça okunması gelmektedir. Daha sonra radyolarından dini yayınlar izin verilmiştir. Din dersleri isteğe bağlı olarak okul programlarına dâhil edilmiştir. İmam Hatip Okulları sayıları artırılmıştır. İlk defa Yüksek İslam Enstitüsü açılmıştır. Diyanet İşlerinin bütçesi genişletilmiş. Vakıflar Umum Müdürlüğüne ayrılan fonlar artırılarak cami ve türbelerin onarılması sağlanmıştır (Bozan, 2007, s.53-54).

DP'nin dini alanda yaptığı bu politik hamlelerin geleneksel cumhuriyet ideolojisi tarafları ve teamülleri tarafından tasvip edildiği söylenemez. Bu tutum Türkiye'nin demokratikleşme sürecini doğrudan etkilemiştir. Ancak her ne kadar demokrasi adına açılımların başlatıldığı görülse de askeri vesayetin varlığı hiç bir zaman önemini yitirmemiştir. Neticede bu kuşatmanın bir sonucu olarak Ordu, 27 Mayıs 1960'da yapılan askeri bir darbeyle yönetime el koymuştur. İhtilal yapma nedenleri arasında gösterilen okullara din dersinin 
konması eğitim alanındaki daralmayı göstermektedir. 1962 yılında yapılan Milli Eğitim Şûrası'nda tarihin en detaylı kararları alınmış; okullardaki sıra düzeninden kıyafete, ders programından öğretmenlerin nasıl davranacağına kadar her türlü hususun kararlara bağlanması yeni bir toplum modeli oluşturma gayretinin belirtisi olmuştur.

Askeri İhtilal ile DP döneminin son bulmasından sonra Yeni Türkiye ve Adalet partileri kurulmuştur. AP (Adalet Partisi), siyasal tavrıyla DP'nin siyasal sosyolojik tabanını devralmış ancak diğer yandan hem parti içinde hem de parti politikaları bağlamında muhafazakâr kesimle arasına mesafe koymuştur. Dolayısıyla AP içinden ve dışından birçok parlamenter yeni siyasi arayışların içerisine girmiştir. Bu siyasal konjonktürde yeni parti kurma çalışmalarına Prof. Dr. Necmettin Erbakan da dâhil olmuştur (Çakır, 2004, s. 544).

Milli Görüş Hareketi'nin düşünsel temelleri her ne kadar geniş bir mazi ile değerlendirilse de Türkiye siyasi tarihinde yer edişi 12 Ekim 1969 Genel Seçimleri "Bağımsızlar Hareketi"ne dayanmaktadır.

Yavuz'a (2004, s. 594) göre Milli Görüş Hareketi "maddi ve manevi kalkınma" olmak üzere iki ana kavram üzerine inşa edilmiştir. Milli Görüş Hareketi etrafında kurulan siyasi partiler dinin siyasi alanda temsilini sağlayarak dindar/ muhafazakâr kesimlerin yerel ve ulusal düzeyde politikaya ve bürokrasiye katılmalarını mümkün kılmışlardır. Bu süreçte isteyerek veya istemeyerek hem geleneksel devlet bürokrasisinin hem de siyasi alanın dini konularda daha hassas olmasına neden olmuşlardır. Milli Görüş Hareketi'nin asıl başarısı ise ekonomik ve kültürel açıdan dışlanmış kitleleri siyasal hayata yerel yönetimlerden başlayarak dâhil etmesi olmuştur. Böylelikle Milli Görüş Hareketi hem muhalif bir merkez olmuş hem de çatısı altında toplanan kitlelerin modernleşmesini sağlamıştır.

Bakacak'a (2010, s. 56) göre Milli Görüş çizgisinde söylem düzeyinde manevi olarak arındırılmış ve pozitifleştirilmiş İslami modernleşmenin içinde korunacak öz sıfatı "milli" dir ancak bu "milli" anlayışının içeriği Cumhuriyet resmi ideolojisinin işaret ettiği millilikten farklıdır.

Diğer yandan Erbakan'ın kullandığı sembol, değer ve örnekler hareketin paradigmal çevresi açısında önemli bulgular içermektedir. Örneğin; Osmanlı-İslami perspektifi hem kimlik hem de düzen arayışında kullanılan geleneksel motifi, Selahaddin Eyyubi ve Ebâ Eyyub El-Ensari gibi şahsiyetlerin öne çıarılması ırki, mezhepsel ve kültürel ayrışmalara karşı "ümmetçilik" anlayışını, "Yeni Bir Dünya" söylemi ve pratikleri ise hareketin küresel çıkışlı 
iddiasını yansıtmaktadır. Necmettin Erbakan, bu sembolik formlar bağlaminda Milli Görüş'ü şu şekilde tarif etmektedir:

Milli Görüş demek "İbrahim milleti” demektir. Görüşs bakış demek, Milli Görüş İslami bakış, İslami Hareket demektir. Milli Görüş adı üstünde milletimizin kendi görüşüdür. Bütün insanllğın bildiği gibi milletimiz asırlar boyu kaba kuvveti değil, hakkı üstün tutan bir zihniyetin temsilcisi olarak insanlık tarihinin en büyük devletleri olan Selçuklu ve Osmanl devletlerini kurmuş, asırlar boyu insanlığa insan haklarn, barış ve adaletin en güzel örneklerini göstermiş, şerefli, parlak bir maziye sahiptir (Tahhan, 2007, s. 280).

Milli Görüş ilerici bir görüştür. Türkiye'yi muasır medeniyetin üstüne çıaracak görüştür. İşte Sultan Fatih. Ne solcu idi, ne liberaldi, ne ortanın sağı idi ve ne de sağın ortasıydı. Milli Görüşçü idi.

Milli Görü̧s Anadolu'ya hakkı, adaleti getiren, Malazgirt zaferini kazandıran görüştür. Sultan Alparslan'ın görüşüdür.

Milli Görü̧s Mustafa Kemal'in öncülü̈̆̈̈̈nde İstiklal Savaşın yapan görüştür (Saadet Partisi, 2003, s. 7-8).

\section{Milli Görüş Partilerinin Eğitim ve Kültür Programları}

Türkiye'de toplumun devlete yönelik talepleri arasında eğitimin özel bir yeri vardır. Eğitim hem bir toplumsal talep hem de devletin ana görevlerindendir. Eğitim, dini bir kolektif bilinç olarak Türkiye'de dindarların sürekli olarak üzerinde tekit ettikleri meselelerden biri olmuştur. Türkiye'de partilerin siyasi anlayışlarını en belirgin olarak yansıttığı konuların başında da eğitim vardır. Çünkü ideolojiler, propaganda ve programlar sayesinde güçlenebilirler. Bu iki özellik de hem partilerde hem de eğitim alanında mevcuttur. Zengin'e (1995, s.161) göre aslında ideolojinin hiç girmemesi gereken alan eğitim ve öğretim sahasıdır. İdeal devlet bilinci olarak "milli” bir eğitim anlayışının varlığı asgari gereklilik olmalıdır.

Türkiye'de eğitim ve kültür bütün toplum kesimlerinin hassas bir şekilde üzerinde durdukları iki önemli alandır. Dolayısı ile dini değer algısının eğitim ve kültür alanlarında değerlendirilişi sadece dindarlar açısından değil, bütün toplumu ilgilendirmektedir. Ancak dindar kesimlerin bir yaşam tarzı olarak benimsediği, antagonistik muhtelif siyasal ideolojilerin ise bir baskı unsuru olarak telakki ettiği "dini değerler görüngüsü" ve "modus vivendi" Türkiye siyasetini çatışmacı bir zemine sürüklemiştir. 
Cumhuriyet sonrası tek partili siyasi hayatın egemen kıldığı ideolojik anlayış uzun süre benliğini devam ettirmiştir. Bu süreçte dindar kesimler bir hak olarak gördükleri eğitim taleplerini ifade etmeye çalışmış ancak başarılı olamamıştır. Türkiye siyaset tarihinde bir kırılma noktası olan çok partili siyasi hayata geçiş ve özellikle partilerin oy/ taraftar kazanma biçim, ilgi ve kültürleri dindar kesimlerin talepleri karşısında politikacıların bir retorikten ziyade, somut siyasi adımlar atmasını sağlamıştır.

Milli Görüş partileri bu noktada bir yandan dindar kesimin değerlerini siyasal bir davranışa dönüştürürken diğer yandan toplumsal bütün içinde eğitim ve kültür alanına ilişkin Batı tarzı yaklaşımlara, sistem bozukluklarına, eğitim müfredatlarındaki aksaklıklara, okul türü ve öğretmen sorunlarına, öğrenci yahut genç nesil değer algısına/ ahlaki donanımına özellikle dikkat çekmiştir.

\section{Milli Nizam Partisi Ĕ̆itim ve Kültür Programlan}

26 Ocak 1970 tarihinde Milli Görüş Hareketi'nin ilk partisi olan Milli Nizam Partisinin kuruluşu, Hareket' in siyasal alana ilişkin birçok konuda kurumsal açıklamalar yapmasını sağlamıştır.

Kısa süreli bir parti tecrübesi yaşayan MNP'nin eğitim ve kültüre ilişkin açıklamaları bu iki alanın birbirinin tamamlayıcısı olduğu algısını oluşturmaktadır. MNP, ilk beyanatı olan kuruluş beyannamesinde eğitim ve kültürle ilgili maddi ilimlerin kurucularının Batılılar değil, Müslümanlar olduğundan, ahlaki alana ilişkin zaaflardan, "Kendi maarifi, kendisi için insan yetiştirmeyen yeryüzündeki tek millet" oluşundan, öğretiminde kendi tarihinin kötülemeye maruz kaldığından, yabancı kültürlerin hâkimiyetinden bahsetmektedir (Milli Nizam Partisi, 1970a, s.6-7).

Parti programında da benzer şekilde yabancı kültür ve millilik vurgusu dikkat çekmektedir. MNP'ye göre yabancı kültür "Batı" demektir. Zararlı her türlü ideoloji ülkenin gayri milli politikalarından dolayı millete bulaştırılmakta ve böylece ülke maddi ve manevi gelişimini sağlayamamaktadır. Dolayısıyla eğitim müfredatında köklü değişimlere gidilmelidir (MNP, 1970b, s. 10).

Öncelikli olarak manevi kalkınmayı hedefleyen MNP, eğitim programıyla ilgili ana gayesini milletin fitratına uygun yüksek ahlak ve fazilet sahibi, kendi kültürüne bağlı, ilmen ileri olan insan yetiştirilmesi olarak belirlemiş 
ve bunların milli bir eğitim politikasıyla gerçekleşebileceğini ileri sürmüştür (Milli Nizam Partisi, 1970b, s.8).

Erbakan, 24 Ocak 1971'de yapılan MNP 1. Büyük Kongresi'nde eğitim alanına sıklıkla değinerek tedrisatın ana fikriyatını oluşturan yabancı cereyanların varlığını milli benliğe aykırı bularak çeşitli sahalarda eleştirmiştir.

Manevi sahada ahlak buhranı memleketimizi sarmış, milletimizi helake doğru götürmeye zorlamaktadır. İçimize giren manevi istila hareketi, maarifimizi elimizden almış, gayrı milli bir maarif yapmıştır. Çocuklarımıza milli ve manevi talim ve terbiye yaptırılmıor. Çocuklarımıza mekteplerimizde dünya görüşü olarak maalesef Mecusilerin, putperestlerin, her türlü yabancı zihniyetin görüşlerine memnuniyetle yer verilmektedir. Bu yanlış ve temelsiz maarif, gençlerimizi kalbi boş yetiştiriyor (Milli Nizam Partisi, 1971, s.3).

\section{MNP Eğitim ve Kültür Programlarnın Değerlendirilmesi: MNP'nin Milli} Eğitim ile ilgili görüşleri siyasal düşüncesinin temel niteliklerini doğrudan betimlemektedir. MNP'nin maarif politikasında maneviyatçı ve kalkınmacı bir muhteva hâkimdir. Sarıbay'a (1985, s. 111) göre MNP'nin eğitim ve kültür anlayışının özünde maddi kalkınmanın yanında "İslam dinine sadık inançlı insan tipi" ve "ahlaki nizam" ön plana çıkmaktadır. Akpınar'a (2009, s. 128) göre MNP'nin ortaya koymuş olduğu ve uzun izahlarda bulunduğu eğitim anlayışı, kurulması düşünülen iktisadi nizamın ahlaki nizamdan geçtiğini göstermektir.

Bu görüşlerin bir sonucu olarak MNP'nin 20 Mayıs 1971'de kapatılmasına ilişkin iddianamede eğitim ve kültür ile ilgili vurgular dikkat çekmektedir. Parti kapatma gerekçesi olarak ülkede manevi eğitimin yapılmadı̆̆ı, okullarda din derslerinin zorunlu olması, diğer okullara tanınan imkânların İmam Hatip Okullarına da tanınması gerektiği ve başını örten öğretmenlerin işlerinden atılmalarının Anayasaya aykırı olduğu politik tutumları gerekçe gösterilmiştir.

MNP’nin eğitim ve kültür ile ilgili öne sürdüğü patoloji, çözümleme ve sorunların çözümüne ilişkin iddiaları gözlemlendiğinde din mefhumu üzerinden yapılan siyasal kısıtlamaları dile getirmesinin yanında, toplumun bütününü esas alan bir siyasal davranış sergilediği görülmektedir. MNP böylelikle dindar kesimin eğitim ve kültüre dayanan taleplerini öngörmüş, dini kolektif bilinç ile açı̆̆a çıkan siyasal kültürün nominelerini oluşturmuş ve öne çıkan toplumsal beklentileri siyasal alana taşımıştır. 


\section{Milli Selamet Partisi Eğitim ve Kültür Programları}

MNP'nin kapatılması üzerine aynı siyasal geleneğin devamı olarak 11 Ekim 1972 tarihinde Milli Selamet Partisi kurulmuştur. Sarıbay'a (1985, s. 127-129) göre MSP'nin ana söylemi "milliliği" esas alarak "Milli Görüsş" düşüncesi etrafında şekillenmiş olmasına rağmen "İslam Ortak Pazarı" söylemiyle Türkiye'nin bilinçaltına İslam dünyası ülküsünü yerleştirmeyi başarmıştır. Dolayısıyla 1970'lerden sonra Batı'ya kuşkuyla bakan, hatta düşmanca duygular besleyen Türkiye'nin yüzünü Batı' dan İslam dünyasına çevirmeye çalışan bir anlayış, başlangıçta MSP camiası etrafında yaygınlaşmaya başlamıştır.

Yavuz'a (2004, s. 594) göre "Yeniden Büyük Türkiye" sloganılla ortaya çıkan MSP, bu büyüklüğün inşası için manevi kimliğin ve İslami kültürün gerekli olduğunu vurgulamıştır. MSP'nin hareket ettiği varsayımda “Müslüman çalmaz, hak yemez ve adaleti gözetir".

MSP, dile getirdiği "manevi kalkınma" ve ona tekamül eden unsurları özellikle koalisyon protokolü, hükümet program ve politikalarında doğrudan gündeme getirilerek bu konuda kendine spesifik bir alan oluşturmuştur.

MSP parti programında eğitimde temel prensiplerini açlklarken Anayasanın 10. maddesinde belirtilen devletin görevleri arasında bulunan fertlerin manevi varlıklarını geliştirme görevine vurgu yaparak yeni nesillerin her şeyden önce edep, ahlak ve fazilet bakımından üstün nitelikli olmaları gerektiğini belirtmiştir.

Eğitim sisteminin içeriğine dikkat çeken MSP, faydasız ve köksüz nazari bilgiler yerine, ilme dayalı maarif politikası izleyeceğini ve üniversitelerdeki araştırmaların yurt problemleri üzerine yöneltileceğini vaat etmiştir.

Din eğitimi ile ilgili olarak da yurttaşların dini ve ahlaki hasletlerle teçhizi için gereken imkânların sağlanarak öğretmen ve din görevlilerinin maddi olarak destekleneceği ifade edilmiştir.

Bu dönemde Kültür Bakanlığı, Milli Eğitim Bakanlığı ile birleşik olduğu için MSP, parti programında kültür ile ilgili olarak özel bir kısım ayırmamış ancak genel olarak milli tarih ve milli kültür vurgusu yapmıştır.

MSP parti programında eğitime ilişkin konuların genelinde ahlak ve maneviyat unsurları sıklıkla işlenmiş ve MSP'nin maarif politikası maarifin her kademesinde ders programlarının milli kültüre göre yeniden tanzimi ve inançlı, çalışkan, vatanperver, milli ahlaka, aile disiplinine bağlı, milli mefkûreye, kültüre ve tarih şuuruna sahip, hakşinas feragatkâr ve fedakâr, ilim, 
teknik ve medeniyet yarışında insanlığa örnek olan nesiller yetiştirilmesi gayesi üzerine kurulmuştur (Milli Selamet Partisi, 1973, s. 25-33).

Erbakan'ın (1973) eğitim alanına ilişkin bazı açıklamaları ise dini kolektivizmden ziyade toplumcu bakış açısını yansıtmaktadır.

Liselerde okuttuğumuz din dersi mühim değildir. Okuttuğumuz sosyoloji dersi din dersinden daha mühimdir. Temel dünya görüşü verirken çocuklarımıza bugün okuttuğumuz sosyolojinin görüşünü verirsek sonra bu çocuklarımız niçin makineli tüfeklerle orta yere çıktığına şaşmayalım! Bu yanlış sosyoloji öğretiminden dönmemiz lazım. Bu sosyoloji öğretimi çocuklarımızı milli bünyesinden çıartıcı mahiyettedir. Maarif sistemimizin manevi yapıyı kuvvetlendirici şekilde değiştirilmesini stratejimizin temel maddesi olarak teklif ediyoruz (s. 42).

MSP seçim beyannamelerinde ise din eğitimi; İmam Hatip Okulları ve Kur'an kursları ile beraber ele alınmış ve İmam Hatip Okullarına yapılan üvey evlat muamelesinin kaldırılacağı, İmam Hatip Okullarının orta kısımlarının tekrar açılacağı, Kur' an kurslarının ülkede yaygın hale getirileceği, üniversiteye girişte mesleki tercih özgürlügünün temin edileceği vaat edilmiştir.

Üniversitelerin yapısıyla ilgili de değerlendirmelerde bulunan Erbakan, üniversitelerde yaşanan ideolojik kamplaşmalara ve bu sebeple oluşan yapılaşmalara eleştiriler getirmiştir (Erbakan, 1975, s. 12-26).

MSP'li Koalisyonlarnn Eğitim ve Kültür Politikalarn: 14 Ekim 1973 Genel Seçimlerinden sonra CHP (Cumhuriyet Halk Partisi)-MSP koalisyonu kurulmuş, MSP bu hükümette 7 bakanlık almış ancak Milli Eğitim Bakanlığını CHP'ye bırakmıştır. Hükümetin Milli Eğitim Bakanı ise Mustafa Üstündağ olmuştur. MSP bu durumda her ne kadar Milli Eğitim Bakanlığı kendisinde olmasa da manevi eğitimle ilgili unsurlarda kendini ön planda tutmaya devam etmiştir (TBMM, 2015, c. 1, s. 577-580).

Bu koalisyon döneminin eğitim ve kültür politikaları arasında başlıca şu icraatlar yer almıştır: 9. Milli Eğitim Şurası kararıyla ahlak dersi 1974- 1975 ders yılı başında ilkokul 4 . ve 5. sinıflarda, ortaokul ve liselerin her sinıfında zorunlu hale getirilmiştir. İmam Hatip Okullarının orta kısımları tekrar açımıştır. Diyanet İşleri Başkanlığı ve Vakıflar Genel Müdürlüğü MSP’li devlet bakanlığına bağlanmıştır. 1973-1974 döneminde 977 olan Kur'an kursu sayısı 
da 1974-1975 döneminde 1.007'ye çıkarılmıştır. Bu dönemde yayınlanan genelge ile vakıf mallarının vakfiyedeki şartları ne ise o gayeye tahsisi ve vakfiyenin gayesinin gerçekleştirilmesi sağlanmıştır. "Müstehcen Neşriyatla Mücadele" adı altında yayınlara ve benzeri organlara müdahale edilerek bu konuda ceza kanunları hükümleri uygulanmıştır (Emre, 2015, c.2).

MSP-CHP Hükümeti'nin bozulmasından sonra AP, MSP, MHP (Milliyetçi Hareket Partisi) ve CGP (Cumhuriyetçi Güven Partisi)'nin bir araya gelmesi ile I. MC (Milli/Milliyetçi Cephe) dörtlü koalisyon hükümetini kurulmuştur. Kurulan hükümette MSP 8 bakanlık almış ancak Milli Eğitim ve Kültür Bakanlığı AP'de kalmıştır. Hükümetin Milli Eğitim Bakanı Ali Naili Erdem, Kültür Bakanı da Rıfkı Danışman olmuştur (TBMM, 2015, c. 2, s.977980).

Koalisyon hükümetlerinde bakanlıklar her ne kadar belli bir uzlaşı mantığı ile paylaştırılsa da koalisyon ortakları arasındaki yaptırımlar ve istekler karşılıklı olarak devam etmektedir. Nitekim MSP, bu durumu kendi istekleri doğrultusunda bulunduğu koalisyon hükümetlerinde açk bir şekilde kullanmiştır (Bellamy, 2012, s. 441-442).

AP-MSP-MHP-CGP Koalisyon Hükümeti'nin eğitim ve kültür politikaları incelendiğinde koalisyon protokolü ve hükümet programı çerçevesinde geliştiği görülmektedir.

İmam Hatip Okullarının sayısında önemli artışlar olmuştur. “Kız öğrencilerin İmam Hatip Okullarına kayıt yaptırma yasağı" Danıştay'ın kararı ile bozularak kaldırılmış böylece yeni dönemde İmam Hatip Okulları kız öğrenci almaya başlamışlardır. İmam Hatip Okullarından mezun olan öğrencilere yine üniversiteye giriş imkânı sağlanmıştır (Milli Selamet Partisi, 1977,s. 38-39). Yüksek İslam Enstitüleri açılmış ve ortaokul ve liselerde ahlak derslerinin özellikle Yüksek İslam Enstitüsü ve İlahiyat Fakültesi mezunları tarafından verilmesi sağlanmıştır (TBMM, 2012, c. 1, s. 542).

MSP, seçim beyannamelerinde öne sürdüğü ortaokul ve lise kitaplarının içeriğinin değiştirilmesi vaadini bu dönemde yerine getirmiştir (MSP, İnanç ve Hamle). 1974-1975 döneminde 1.007 olan Kur'an kursu sayısını 1975-1976 döneminde 1.037'ye ve 1976-1977 döneminde 1.267'ye çıkarılmıştır. Yurtdışında İslam ülkelerinde tahsil yapanların diplomalarının yurt içinde de denkliği sağlanmıştır. Vakıf eserlerinin vakıf şartnameleri dışındaki gayeler için kullanılmasına izin verilmemiştir (Emre, 2015, c.3). 
I. MC Hükümeti 5 Haziran 1977'de yapılan milletvekili genel seçimlerine kadar sürmüştür. Seçim sonrasında AP, MSP ve MHP ile bir araya gelerek II. MC (Milli/Milliyetçi Cephe) olarak adlandırılan üçlü koalisyon hükümetini kurmuştur. Kurulan hükümette MSP 7 bakanlık almış ancak Milli Eğitim ve Kültür Bakanlığı yine AP'de kalmıştır. Hükümetin Milli Eğitim Bakanı Nahit Menteşe, Kültür Bakanı da Avni Akyol olmuştur (TBMM, 2015, c.2, s.13231326).

Kurulan hükümetin eğitim ve kültür politikaları incelendiğinde I. MC Hükümeti'nin devamı niteliğinde olduğu gözlemlenmektedir. Akpınar'a (2009, s. 140) göre Erbakan, manevi kalkınma sürecinde kültürel alana verdiği öncelik ile sembolik kültürel sermayenin milli ve İslami bir temelde yeniden üretilmesini esas almışır. Böylece "manevi kalkınma" söylemi yeni birikim yapılarını harekete geçirmede kültürel bir işleve sahip olmuştur.

Hükümetin eğitim ve kültürle ilgili olarak Müslüman ülkelerle işbirliği geliştirmesi, ticari ve kültürel anlaşmalar imzalaması, ilmi ve ahlaki eserlerin okutulmasına ilişkin konulan yasakları kaldırması ise diğer politikalarındandır (Milli Selamet Partisi, 1978, s.60-63).

MSP Eğitim ve Kültür Programlarnnın Değerlendirilmesi: Milli Görüş Hareketi'nin ikinci partisi olan MSP, siyasal alanda hem seçim hem de meclis ve iktidar tecrübesi yaşamıştır. Bu tecrübelerle MSP, siyasal kültür anlayışını birçok alanda pratize etme imkânını sahip olmuştur.

MSP'nin eğitim anlayışının temelini "Önce Ahlâk ve Maneviyat" sloganı oluşturmaktadır. MSP, parti programı hedefleri bakımından MNP'ye göre daha açık ve somuttur. Bu dönemde MSP'nin eğitimle ilgili siyasal tavrının yanı sıra Erbakan'ın manevi kalkınma adı altında öne sürdügü politik-kültürel tutum seçmenler tarafından siyasal bir davranışa dönüşmüştür.

Çaha'ya (2004, s. 481) göre İmam Hatip Okullarının sayılarındaki artış ve bu okulların giderek rekabet şartlarına uyum sağlama isteği, İslami tonu ağır basan renklerin devlet alanına rahatça taşınabilmesi şansını doğurmuştur.

Kültür politikalarında ise MSP'nin makro politik siyasi duruşu kolektif bilinç olarak İslam merkezli olduğunu göstermektedir. MSP'nin kültür olarak ileri sürdüğü görüş, bir üst tasnifle "ümmetçiliğgi" esas almaktadır. Bunun siyasal karşılığı olarak MSP, “İslam Ülkeleri Arasında Kültürel İşbirliği Teşkilatı” kurulması hedefini, idealize ettiği “Yeni Bir Dünya”nın bir basamağı olarak görmüştür. 
Kavramsal olarak fazilet, edep, iffet, hayâ gibi kavramlar eğitimde kültürel bir aktarım olarak öğrenilmesi gereken unsurlardandır. Bu bakımdan MSP'nin kültür anlayışı analiz edildiğinde İslami terminolojinin hâkim olduğu, makro politik bir siyasal kültür ortaya koyduğu ve yaydığı gözlemlenmektedir.

MSP'nin koalisyon ortağı olduğu bu tarihsel düzlemde özellikle eğitimle ilgili birbirini pekiştiren adımların atıldığı ve bu adımların statikleşme durumu karşısında da koalisyondan çekilmeyi bir tehdit unsuru olarak kullandığı görülmektedir. Başka bir yönü ile MNP döneminde bağımsız değerlendirilen eğitim; MSP döneminde ekonomi ile paralel politik bir zemin üzerine oturtulmuştur (Wendt, 2013, s.577).

\section{Refah Partisi Ĕ̆itim ve Kültür Programlan}

12 Eylül 1980 Askeri Darbesi ile bütün partilerin kapatılmasından sonra 19 Temmuz 1983 tarihinde Milli Görüş Hareketi'nin üçüncü partisi olan Refah Partisi kurulmuştur.

RP, Milli Görüş çizgisinin otantik kimliğini koruyarak siyasal kültür anlayışını sürdürmüştür. Çakır'a (2004, s. 564-565) göre RP, Batı karşıtı bir parti olarak öne çkmıştır. Türkiye'nin Ortak Pazar ile Avrupa Topluluğu üyeliğine ve Gümrük Birliği Antlaşmasına şiddetle karşı çıkan Milli Görüşçülerin esas meselesi ise ABD ve İsrail'dir.

Milli Görüş partileri arasında RP, Türkiye'nin ve İslam dünyasının sorunlarını çözmek amacıyla ilk sistematik çıkışını "Adil Düzen" söylemiyle bu dönemde yapmıştır. Erbakan'a göre Adil Düzen'in tek gayesi herkese iyilik ve saadet getirmektir. Bu yüzden sanayileşmiş Batı ülkeleri ve gelişmekte olan ülkelerde barış içinde en iyi dostluk münasebetleri yürütülecektir ve bu meyanda bilhassa ticari, teknoloji ve ilmi araştırmalar sahalarında her türlü iş birliği teşvik edilecektir (Refah Partisi, 1991).

Adil Düzen' in alt kategorilerinden "Dini/Ahlaki Düzen" ile "irfan" sahibi bireyler ve inançlı kadrolar yetiştirileceği, üretimin yanında eğitime, manevi terbiye ve bu bağlamda nefis terbiyesine büyük önem verileceği, ifade edilmiştir (Erbakan, 1991, s.92). 
RP yayınladığı icraat programında maddi ve manevi kalkınmayı gerçekleştireceğini, manevi kalkınma hamlesini de planlı yürüteceğini ve Müslüman ülkelerle bu bağlamda işbirliği yapacağın belirtmiştir (Refah Partisi, 1990, s.41).

RP, 20 Ekim 1991 Genel Seçim beyannamesinde eğitim ve kültürle ilgili olarak eğitimin toplumun inanç ve değer ölçülerine göre yapılmasına, öğrencilere milli kültürün tanıtılması ve tarih şuuru verilmesine, Din ve Ahlâk Kültürü derslerinin geliştirilmesine ve bu derslerin ihtisas sahibi ehil hocalar tarafından okutulmasına özen gösterilmesine değinilmiştir (Refah Partisi, 1991).

$R P$ 'nin eğitim alanında ortaya koyduğu yeni kurumsal öncelikler de dikkat çekmektedir. Buna göre herkes okuyacağı okulunu, bilgi edineceği öğretmenini ve eğiticiyi kendisi seçme hakkına sahip olacaktır. Devletin resmi dilinin Türkçe olacak ancak mahalli meclislerde Türkçe ile birlikte istenilen dilde de öğretime izin verilecek ve dil özgürlüğünü esas olacaktır. Emperyalist kültürlerin egemenliğini sağlayan yükseköğretimdeki yabancı dille öğretime son verilecektir (Refah Partisi, 1991, s.91).

24 Aralık 1995 Genel Seçimleri'nden sonra RP, 30 Haziran 1996 tarihinde DYP (Doğru Yol Partisi) ile koalisyon oluşturarak 54. Türkiye Cumhuriyeti Hükümeti'ni, diğer adıyla Refah-Yol Hükümeti'ni kurmuştur. Kurulan hükümette RP, Kültür Bakanlığı dâhil 18 bakanlık almış ancak Milli Eğitim Bakanlığ 1 DYP'de kalmıştır. Hükümetin Kültür Bakanı İsmail Kahraman, Milli Eğitim Bakanı ise Mehmet Sağlam olmuştur. RP, seçim kampanyalarında her ne kadar manevi kalkınma hamlesinin yapılmasına ve din eğitimiyle ilgili birçok hususu dile getirse de kendi kurduğu hükümette Milli Eğitim Bakanlığını almamıştır (TBMM, 2015, c. 3, s. 2349-2352).

Dönemin Kültür Bakanlığı politikalarıyla ilgili olarak Bodrum Kalesi ve Trabzon Ayasofya'sı hakkındaki polemikler en çok gündemde kalan konulardır. Yine bu dönemin kültür politikalarıyla ilgili olarak D-8 ülkeleri Kültür Bakanları Toplantısı ve D-8 ülkeleri "I. Kültür ve Sanat Şöleni" yapılmıştır (Refah Partisi, 1997, s.428-429).

Eğitimle ilgili olarak bu dönemde en fazla üzerinde durulan meselelerin başında kesintisiz 8 yıllık eğitim, İmam Hatip Okullarının durumları, din eğitimi ve başörtüsü meselesi gelmektedir. 
Öğretmen atamalarıyla ilgili Meclis'te yapılan tartışmalara Milli Eğitim Bakanı Mehmet Sağlam, atanan 11.000 öğretmen içerisinden 4.000'e yakınının eğitim fakültesi mezunu diğerlerinin de çeşitli fakültelerden mezun olduğunu (TBMM Tutanak Dergisi, 1997, c. 21, s. 218-219) ancak bu atamalarda YÖK'çe denkliği olmayan El-Ezher Üniversitesi gibi üniversitelerden gelen hiç kimsenin atanmadığını belirterek cevap vermiştir (TBMM Tutanak Dergisi, 1996, c. 17, s.272-274).

28 Şubat 1997'de Genel Kurmay Başkanlığının MGK'da (Milli Güvenlik Kurulu) hükümetin durumuna ilişkin sunduğu 18 maddelik teklif ve tedbirlerin ağırlık noktasını eğitim ve din faktörleri oluşturmaktadır. Nitekim MGK'da Genel Kurmay Başkanlığının hükümete ilişkin verdiği “18 Maddelik Teklif ve Tedbirler" içerisinde eğitimle ilgili olarak tarikatlarla bağlantılı özel yurt, vakıf ve okulların denetim altına alınıp Milli Eğitim Bakanlığına devrinin sağlanması, 8 yıllık kesintisiz eğitimin tüm yurtta uygulamaya konulması ve Kur'an kurslarının Milli Eğitim Bakanlığının sorumluluğu altında faaliyet göstermeleri, din adamı yetiştirmekle yükümlü Milli Eğitim kuruluşlarının ihtiyaç düzeyinde tutulmaları, kıyafetle ilgili kanuna aykırı olan uygulamalara mani olunması ve Anayasa Mahkemesi kararlarının taviz verilmeden uygulanması konularına vurgu yapılmıştır (Kazan, 2003, s. 323-324).

RP Eğitim ve Kültür Programlarnnn Değerlendirilmesi: RP süreci Milli Görüş Hareketi çizgisinin eylem, söylem ve dinamikleriyle en dorukta olduğu dönemdir. Refah-Yol iktidarı da dindar kesimlerin kolektif bilincini siyasi alana sistematik olarak yansitan bir tecrübe olmuştur.

Milli Görüş Hareketi çizgisinde RP'nin program ve yayınlarında MNP ve MSP'ye göre dini sembol ve kavramları siyasette daha açık bir şekilde yansittığını göstermektedir. RP'nin özellikle gençlerin yetiştirilmesinde vurguladığı hakkı üstün tutma, nefis terbiyesini esas alma, cihat gayreti içinde, mücahit ruhlu ve maneviyatçı olma mottoları devletin geleneksel ideolojisini zorladığını tezini desteklemektedir.

54. Hükümet koalisyon protokolünde genç nesillerin yetiştirilmesi hususunda Milli Görüş geleneğinin otantik ideolojik algısından farklı olarak manevi ve ahlaki değerlerine bağlı genç yetiştirilmesi yanında "laik, Atatürk ilke ve inkılâplarına bağlı" genç prototipi ortaya konmuştur. Bu durumun psikopolitik durumu değerlendirildiğinde RP'nin ideolojik bir yumuşamadan çok, 
devletin Atatürkçü ideolojik yapısının temayüllerini manipüle ederek tevil ettiğini göstermektedir.

RP, MSP'nin koalisyon ortağı olduğu hükümetlerde olduğu gibi RefahYol Hükümeti'nde de eğitimle ilgili olarak kendisine dolaylı bir etki alanı oluşturmuştur. Ancak RP'nin iktidara gelmesiyle başlayan 28 Şubat süreci ve doğurduğu sonuçlar eğitimin doğrudan odak haline geldiğini göstermektedir. Netice itibariyle RP'nin Milli Eğitim Bakanlığını almaması öncelik etkisini gösterdiği gibi politik bir tavır olarak da değerlendirilebilir.

28 Şubat'ta MGK'da Genel Kurmay tarafından yapılan öneri maddelerin ağırlık merkezinin eğitim konuları olması iki değerlendirmeyi ön plana çımaktadır. Birincisi, müdahalenin özellikle eğitim düzlemi üzerinden yapılması eğitimin devletin diğer kurumları tarafından da önemle izlendiğini ve hassas bir alan olduğudur. İkincisi de Milli Görüş partileri müdahalenin olduğu zamana kadar ki dönemlerinde eğitimle ilgili önemli adımlar attığı ve karşıt ideolojileri rahatsız ettiğidir.

Kültürle ilgili olarak D-8'ler üzerinden kültür faaliyetlerinin planlanması ümmetçi bir İslami geleneğinin oluşturulması yönünde çalışma yapıldığı değerlendirmelerini doğrulamaktadır. Yine bu dönemde Meclis'te opera ve bale gibi alanlar hakkında yapılan olumsuz kanaatlerin belirtilmesi RP'nin kültür portföyünü ve milli kültür algısını ortaya koyan önemli unsurlardır.

\section{Fazilet Partisi Eğitim ve Kültür Programlarn}

RP'nin Anayasa Mahkemesi tarafından 16 Ocak 1998'de kapatılmasından sonra 17 Aralık 1997'de Milli Görüş Hareketi'nin dördüncü partisi Fazilet Partisi siyaset sahnesinde yerini almıştır. Milli Görüş lideri Necmettin Erbakan'ın RP'nin kapatılma kararıyla beraber siyasi yasaklı hale geldiği FP döneminde insan hakları, demokrasi ve özgürlük söylemleri ağırlıklı olarak gündeme getirilen konulardan olmuştur (Fazilet Partisi, 1998b).

FP bu dönemde Milli Görüş Hareketi çizgisindeki diğer partilerden farklı olarak dinsel öğelerin kullanımını minimize etmiş, eğitimle ve kültür ilgili olan kısmıla YÖK'ün tutumları, üniversitelerdeki başörtüsü sorunu, zorunlu 8 yıllık kesintisiz eğitimin ve İmam Hatip Okullarının durumları konularına insan hakları ve demokrasi merkezli bir üslup geliştirmiştir.

Milli Görüş Hareketi çizgisinde FP'nin siyasetteki bu yöntem değişikliği parti programına, seçim beyannamesine ve diğer yayınlarına da yansımıştır. 
FP parti programında eğitim ile ilgili olarak özellikle dini konulara doğrudan atıf yapılmamış, din eğitiminin bahsi geçmemiş ve manevi eğitim adı altında daha önceki parti programlarında yer alan gençliğin sahip olması gereken dini/ahlaki hasletlere değinilmemiştir (Fazilet Partisi, 1998a).

FP Genel Başkanı Mehmet Recai Kutan'ın 17 Aralık 1998'de yapmış olduğu basın toplantısında Milli Görüş Hareketi'nin ideolojik otantikliğine paralel olarak ilköğretim sistemini eleştirerek İmam Hatip Okullarının orta k1sımlarının kapatılması uğruna zorunlu 8 yıllık kesintisiz eğitime geçildiğini ve zorunlu kesintisiz eğitimin geri kalmış eğitim sistemi uygulaması olduğunu ileri sürerek eğitime ilmi ve milli bir anlayış getirilmesi gerektiğini savunmuştur (Fazilet Partisi, 1998b, s. 59-60).

Kutan, eğitimde mesleki ve teknik eğitime önem verilmesinin gerekliliğini öne sürmüş ancak buna binaen din eğitiminin mesleki eğitim olarak değerlendirilmemesi gerektiğini belirtmiştir. Devlete din eğitimi konusunda faklı bir gereklilik yükleyerek devletin toplumda çocuklarının din eğitimi almasını isteyenlere bu imkânı sağlaması gerektiğini ve devletin din eğitiminde İmam Hatip Okullarını desteklemesi gerektiğini ileri sürmüştür (Fazilet Partisi, 1998b, s. 61-63).

FP, 18 Nisan 1999 Milletvekili Genel Seçimi öncesi yayınladığı seçim beyannamesinde eğitim konulu ana başlı̆̆ daha önceki seçim beyannamelerinden farklılıkla "Genel Olarak Eğitim, Mesleki Eğitim, Din Eğitimi ve Yüksek Öğretim Kurumu" alt başlıkları ile tasnife gitmiştir. (Fazilet Partisi, 1999, s. 109-115).

Beyannamede eğitimde özgür düşünceli, kendi başına karar verebilen, kendi toplumunun ve evrensel anlayışı ufuklarından haberdar olan, donanıml, yeterli ve yetenekli kişileri yetiştirmenin ehemmiyetine ve bu eğitim anlayışının çoğulcu ve katılımcı yönünün geliştirilmesine değinilmiştir (Fazilet Partisi, 1999, s. 109-110).

FP'nin ortaya koyduğu görüşlerde YÖK, hiç olmadığı kadar teferruatlıdır. YÖK başlığının içinde YÖK'ün ideolojik zihniyeti, bilimden uzaklaşması, anti-demokratik uygulamaları ve yeniden yapılandırılması gibi konular dikkat çekmektedir (Fazilet Partisi, 1999, s. 115-117).

FP'nin ortaya koymuş olduğu ifadelerde en çok dikkat çeken alan ise kültür olmuştur. Kültür alanına ise Milli Görüş partilerinin daha önceki seçim beyannamelerindeki açıklamalardan farklı olarak daha uzun yer verildiği ve 
bu alanla ilgili somut hedeflerin konulduğu gözlemlenmektedir (Fazilet Partisi, 1999, s. 122-127).

Kültür alanına ilişkin icraat programında ise plastik sanatlar ve klasik Türk-İslam sanatları bağlamında sanat galerilerinin teşvik edileceği, yerli sinemasının destekleneceği, milli musikinin gelişimini amacıyla yeni tarz konservatuarların kurulacağı, tiyatroların gelişiminde rekabetçi bir yapı oluşturulacağ 1 ve milli kültürün temel değerlerinin işleyen animasyon filmlerin destekleneceği değinilen önemli noktalardandır (Fazilet Partisi, 1998a, s.1112).

FP Eğitim ve Kültür Programlarnnn Değerlendirilmesi: FP dönemi, Milli Görüş Hareketi çizgisinde söylem, eylem ve üslup bakımından yumuşak tonajlı bir siyasi tutum içinde olduğu sürece karşıllk gelmektedir. Her ne kadar yapılan sözlü açıklamalarda Milli Görüş Hareketi'nin siyasi ve ideolojik çizgisine paralel parametrelerin kullandığı gözlemlense de yazılı kaynaklarda bu özellikler açk olarak görülmemektedir.

FP, parti programlarında eğitimin form ve muhteva yönü analiz edildiğinde eğitimin önceki Milli Görüş partilerinin parti programlarında olduğu gibi ekonomi alanından sonra biçim olarak en uzun, içerik olarak da en teferruatlı alan konumunda olduğu gözlemlenmektedir.

Milli Görüş partileri tarafından her dönem eleştirilen kesintisiz 8 yıllık eğitim bu dönemde pedagojik ve istihdam açısından, YÖK'ün ideolojik tutumları ve üniversitelerdeki başörtüsü sorunları da insan hakları ve özgürlükler açısından ele alınarak kritize edilmiştir. Kur'an kurslarının durumları ise FP'nin asgari işlediği konulardan biri olmuştur.

FP'nin parti programı ve seçim beyannamesi analiz edildiğinde konuların RP’ye göre farklı bir yöntemle ele alındığı ve yansıtıldığı gözlemlenmektedir. RP döneminde idealize edilen "Adil Düzen" söylemi, erdemli/şuurlu insan olma özellikleri ve dini motifler FP'nin parti programı ve seçim beyannamesinde işlenmemiş, önceki betimlemelerden farklı olarak hoşgörülü ve barışçıl insan olma özelliği ön plana çıkarılmıştır. Adil Düzen söylemiyle sosyolojik bir karşılık bulan RP, bu söylemle kendi tabanını mobilize etmiş, toplumu da kendisine oy verecek eğilime getirerek siyasal toplumsallaşmayı gerçekleştirmiştir. Ancak 28 Şubat sürecinin etkileri sebebiyle farklı bir strateji izleyen FP'nin söylem ve içerik bakımından bu görünümden uzak olduğu söylenebilir. 
FP, parti programı ve seçim beyannamesinde kültür alanı RP döneminde yapılan makro söylemlerden farklı olarak yerel ve akraba topluluklarla bağlantılı kültürel faaliyetleri kapsayan bir icraat programı hazırlamıştır. Önceki dönemlerde vurgulanan ümmetçi anlayış ise bu dönemde dile getirilmemiştir.

Medya ve kültür araçlarının eleştirildiği önceki Milli Görüş partilerinden farklı olarak FP'nin faaliyet bazında sinema, tiyatro ve müzik alanlarını yerel açlımlarla desteklediği ve "emperyalist" tekelciliğe karşı farklı alternatifler oluşturmaya çalıştığı dikkat çekmektedir.

FP'nin öne sürdüğü vaatler ve siyasi tavır her ne kadar Milli Görüsş'ün geleneksel anlayışının dışında kalsa da FP'nin kapatılmasına gerekçe olarak gösterilen "laik cumhuriyet ilkesine aykırı eylemlerde bulunma" kararı hâkim devlet ideolojisi tavrının baskınlığını ve Milli Görüş Hareketi'ne bakışını göstermektedir.

\section{Saadet Partisi Eğitim ve Kültür Programlarn}

FP'nin 22 Haziran 2001'de kapatılmasının ardından 20 Temmuz 2001'de Milli Görüş Hareketi'nin beşinci partisi olan Saadet Partisi kurulmuştur. Uzun bir süreci içine alan Saadet Partisi dönemi kuruluş yıllarından günümüze gelişen belirgin birçok siyasi olay sebebi ile konjonktürel bir değerlendirmeyi gerektirmektedir. İlk yıllarında Necmettin Erbakan'ın siyasi yasağının devam etmesi ve ayn toplumsal tabana hitap eden AK Partinin kurulması Saadet Partisinin daha sert ve ayırt edici bir üslup benimsemesine sebep olmuştur.

İlk dönem Saadet Partisi eğitim ve kültür programlarında konu olarak 8 yıllık kesintisiz eğitim, üniversitelerdeki başörtü sorunu, üniversiteye giriş s1navlarındaki katsayı uygulamaları, Kur'an öğretimindeki yaş sınırı ve din eğitimi işlenmiştir (Sadet Partisi, 2001).

Parti programında eğitim ve kültürle ilgili olarak insanlara bazı yüksek değerlerin kazandırılması için eğitim ve öğretime terbiye boyutunun katılması, çağın gereklerine uygun bir eğitim reformunu gerçekleştirilmesi, eğitim ve öğretim özgürlüğü, eğitim kurumlarında insan hakları ve demokrasi ile din kültürü ve ahlak derslerinin okutulmasının zorunluluğu, zorunlu eğitimin 5+3 şeklinde kademelendirilmesi, yükseköğretime fursat eşitliğinin sağlanması hususları dikkat çekmektedir (Sadet Partisi, 2001, s. 13-15). 
Saadet Partisi, 3 Kasım 2002 Milletvekili Genel Seçimleri öncesi yayınladığ1 seçim beyannamesinde eğitim ve kültürle ilgili olarak önceki Milli Görüş partilerinde işlenen "Önce Ahlak ve Maneviyat" vurgusuna ek olarak "bilgi" mefhumunu gündeme getirilmiştir (Saadet Partisi, 2002, s. 30).

Saadet Partisi, yayınladığı bu beyanname ile FP'den önceki Milli Görüş partilerinin söylem tarzına tekrar döndüğünü göstermektedir. Yine beyannamede konu bazında ekonomik unsurların ağırlıklı olduğu gözlemlenirken kültür alanıyla ilgili olarak teferruatlı bilginin verilmediği dikkat çekmektedir (Saadet Partisi, 2002, s. 36).

Saadet Partisinin (2004) "AB'nin Türkiye İlerleme Raporu" çerçevesinde yapmış olduğu araştırmasının bir kısmı AK Parti iktidarına yönelik kültür eleştirisi barındırmaktadır:

Avrupa Birliği... önce bir ekonomik işbirliği olarak başlayan bu kuruluş, daha sonra bu birlikteliği, siyasi ve sosyo-kültürel alanlara da taşımıştır. $A B^{\prime}$ ye uyum çalışmalar sürecinde, Türk milletinin örf ve adetlerinde, ahlaki değerlerinde ve hatta inancında büyük ölçüde değiş̧meler olacağının beklenilmesidir (s. 7-10).

Saadet Partisi, eğitim ve kültür alanlarına ilişkin 12 Haziran 2011 Genel Seçimleri'ne kadar benzer içeriklerden oluşan seçim beyannameleri hazırlamıştır. Ancak meslek liseleri için uygulanan kat sayı uygulamasının değişmesi ve İmam Hatip Liselerinden mezun olanların üniversiteye girişteki engellerinin kalkması, başörtüsü meselesinin çözülmesi, Kur'an eğitiminde ideolojik baskıların önlenmesi eğitim ve kültür alanında yeni mecraların açılmasını, yeni söylem ve politik tutumların geliştirilmesini sağlamıştır (Saadet Partisi, 2011, s. 40-42).

Dolayısı ile Saadet Partisinin ikinci evresinde eğitim ve kültür alanlarında farklı odaklara eleştiriler getirmeye başlamıştır. Bu yönü ile 24 Haziran 2018 Genel Seçimleri beyannamesi yaşanan siyasi değişimlere ilişkin çeşitli bulgular sunmaktadır.

Eğitimin temel gayesi geleneksel siyasi yaklaşımda olduğu gibi "ahlaklı ve liyakat sahibi nesiller" yetiştirmek olarak tanımlanmıştır. Eğitim sistemi ve sık değişen Milli Eğitim bakanları için eğitimde kaosun hâkim olduğu ve öğretmen saygınlığının giderek azaldığı ifade edilmiştir. Üniversitelerin toplumsal fayda, kalkınma, bilim ve bilgi üretmek yerine, siyasal kutuplaşmanın 
ve çekişmelerin merkezi haline geldiği eleştirisi yapılmıştır. Gerek üniversitelerde gerekse eğitimin diğer kademelerinde nitelik sorunu sıkça dile getirilen konuların başında gelmektedir. YÖK'ün kaldırılması her Milli Görüş partisinde olduğu gibi bu beyannamede de yerini alır iken teknoparklar ve buna bağlı olarak iş dünyası ile ilişkiler ilk defa Saadet Partisinin özel gündemi olarak eğitim programlarında yerini almıştır (Saadet Partisi, 2018, s. 131-142).

Her ne kadar kültür alanına ilişkin vaatler beyannamede az olsa da kavram olarak "kültür" en fazla kullanılan terimlerin başında gelmektedir. Saadet Partisinin yeni dönem vizyonunda kültür birçok alanı ihtiva eden bir anlam bütünlügü içerisinde kullanılmıştır. Kültür tematiğinde getirilen eleştirilerin odağında ise kutuplaşma, toplumsal yozlaşma ve aile mefhumun dejenerasyonu gelmektedir (Saadet Partisi, 2018).

Saadet Partisi Ĕ̆itim ve Kültür Programlarnnn Değerlendirilmesi: Saadet Partisi dönemi, Milli Görüş Hareketi çizgisinde söylem ve eylem bakımından RP ve MSP dönemi dinamiklerinin yeniden harekete geçirildiği otantik bir sürece karşllık gelmektedir.

Saadet Partisi dönemi, hazırlanan seçim beyannameleri çerçevesinde değerlendirildiğinde her genel seçim için farklı parametrelerin ele alındığı gözlemlenmektedir. Özellikle 22 Temmuz 2007 Genel Seçimleri öncesi hazırlanan seçim beyannamesi AKP'ye karşı oluşturulmuş reaksiyonel bir siyasi tavri yansitmaktadir.

Saadet Partisi dönemi, eğitim programları açısından değerlendirildiğinde 3 Kasım 2002 seçim beyannamesinde bulunan eğitim kurumlarında insan hakları ve demokrasi derslerinin din kültürü ve ahlak dersleri gibi zorunlu olarak okutulması beyanı Milli Görüş partilerinin yaşadığı fikri, siyasi ve hukuki konjonktürleri ortaya koymaktadır. Yine Saadet Partisinin eğitim alanı ile ilgili ele aldığı meselelerin otantikliğini koruduğu ama biçimsel değişikliklere uğradığı gözlemlenmektedir. Örneğin 3 Kasım 2002 seçim beyannamesinde belirtilen $5+3$ eğitim sistemi modeli 12 Haziran 2011 seçim beyannamesinde $4+3+3$ şeklinde idealize edilmiştir. Bu eğitim sistemi modelinin ortaya konmasından sonra ifade edilen İmam Hatip Okulları vurgusu ise Saadet Partisinin Milli Görüş Hareketi çizgisindeki kolektif düşüncesinin özünü korunduğu analizini teyit etmektedir.

Diğer yandan Milli Görüş geleneğinde İmam Hatip Okulları tikel ve reel politik bir unsur olmaktan ziyade "manevi kalkınma" bütününün bir parçası 
olarak değerlendirilmiştir. Dolayısıyla parti programları ve beyannameler beraberce ele alındığında İmam Hatip Okulları sayılarının artması toplumsal yozlaşma, adaletsizlik, değerlerin tahribatı, aile mefhumunun zayıflaması gibi toplumsal/manevi sebepler gösterilerek eğitim ve kültür alanındaki eleştirileri azaltmak yerine artırmıştır.

Saadet Partisi dönemi kültür programları ele alındığında ise FP dönemi ele alınan kültür konularından hiçbirinin gündeme alınmadığı dikkat çekmektedir. Yine bu dönemin kültür alanı ilgili başka bir özelliği konuların yüzeysel ve soyut olarak ele alınmış olmasıdır.

Saadet Partisi döneminde eğitim ve kültür, RP dönemindeki anlayışa tekrar geri dönmüştür. Genç yetiştirme profili tekrar İslami terminoloji üzerinden yapılmaya başlanmış; kültür, İslam'ın şefkat, sevgi ve hoşgörü temellerine dayanan teşekkülü şeklinde tafsil edilmiştir.

\section{Sonuç}

Bu makalede, Milli Görüş partilerinin eğitim ve kültür alanlarına ilişkin yaklaşımlarının değerlendirmeleri yapılmıştır. Analizler doğrultusunda kapatılan her Milli Görüş partisinin farklı formlarda yeniden açılması çeşitli farklılıkları, konjonktürüne göre söylem değişikliğine gittiği ve görüş bildirilen alanlarla ilgili dönemsel açıklamaların yapıldığı tespit edilmiştir. Bütün bu değerlendirmeler ışığında çalışmanın ana merkezini yöntem olarak Milli Görüss partilerinin eğitim ve kültür programlarının konjonktürel değerlendirmesi oluşturmaktadır.

Milli Görüş Hareketi'nin ilk partisi olan MNP'nin politik tutumlarının tevcihini "milli olan" ve "milli olmayan" ayrımı oluşturmaktadır. MNP, eğitim ile "inançlı insan" tipi/profili oluşturmayı hedeflemektedir. Bu anlayışının makro düzeydeki yansımasını ise "ahlak nizamı" oluşturma projesidir. MNP'nin parti programında tafsile en fazla ağırlık verdiği konu da eğitim olmuştur ve bu alanla ilgili yapmış olduğu açıklamalar partinin kapatılmasinda en fazla üstelenen unsurlardır.

MSP'nin eğitim anlayışının temelini "Önce Ahlak ve Maneviyat" sloganı oluşturmaktadır. Milli eğitim ile ulaşılmak istenen ana gaye de "yeni nesillere, milli ahlakın ve manevi hasletlerin intikal ettirilmesi" olarak belirtilmiştir. MSP, programına bu hedefler dâhilinde MNP'ye göre daha açık ve somut hedefler koymuştur. Kültürle ilgili olarak da dönemin en önemli projesi İslam 
ülkeleri arasında kurulması düşünülen kültürel işbirliği ve teşkilatıdır. Bu aynı zamanda ümmetçi bir geleneğin takip edildiğinin göstergesi durumundadir.

$R P$, eğitim alanı ile ilgili olarak diğer Milli Görüş partilerine göre en sistematik çıkışını yapmıştır. RP, “Adil Düzen” projesi kapsamında “İlmi/Ahlaki Düzen" temellendirmesi yapmaya çalısmıştır. Ancak bu projenin "ideal düzen" vurgusu sebebiyle konuları siyaset üstü bir üslup ile ele alması somut, güncel ve politik gündem açısından anlaşlabilir kılmamıştır. Kültürle ilgili olarak da bu dönemde en göze çarpan olaylar D-8 bünyesinde Kültür Bakanlıkları düzeyinde yapılan çalışmalar ve Meclis'te opera ve bale gibi alanlar hakkında yapılan olumsuz kanaatlerin belirtilmesi olmuştur. Bu olgular RP'nin, kültür portföyünü ve milli kültür algısını açıkça ortaya koymaktadır.

Yine bu dönemde yaşanan "28Şubat post-modern müdahalesi" ve müdahaleye konu olan MGK'da Genel Kurmay tarafından yapılan öneri maddelerinin ağırlıklı olarak eğitim ve kültür üzerinden yapılması Milli Görüş partilerinin bu alanlara ilişkin hem siyasi hem de toplumsal etkiyi sağlayabildiğini göstermektedir.

FP, Milli Görüş geleneğinde farklı bir siyasi tarz ortaya koymuştur. Bu dönem Milli Görüş Partileri açısından dini öğeler minimize edilmiş ve siyasi üslup evrensel değerler üzerinden şekillenmiştir. Kültürle ilgili olarak da edebiyat, folklor, resim, müzik, sinema ve tiyatronun öneminden ve geliştirilmesinden bahsedilmesi değişimin boyutların göstermektedir.

Saadet Partisi döneminde ise eğitim ve kültür iki ayrı evrede değerlendirilmiştir. 12 Haziran 2011 Seçimlerine kadar devam eden ilk evrede RP dönemindeki siyasi tavra tekrar geri dönmüştür. İkinci evre ise Türkiye' de yaşanan siyasal gelişmeler karşısında değişen bir parti vizyonu algısıdır. Bu dönemde eğitim ve kültür alanında Saadet Partisinin belirli kesimleri merkeze almaktan ziyade daha toplumcu, daha geniş kesimlere hitap eden bir bakış açısı ortaya koymaya çalıştı̆̆ tespit edilmiştir.

Tekin'e (2017, s. 224) göre Milli Görüş partilerindeki değişimlerin ana ekseninde Türkiye' de siyasal ve toplumsal alanın maruz kaldığı baskılar vardır. Dolayısı ile partilerin kapatılma gerekçeleri de göz önüne alındığında belli bir siyasi sıkışıklığı gidermek, partilerin üzerine odaklanan tartışmaları aşmak, meşruiyet zeminini korumak ve görüşlerini topluma aktarabilmek için formel yeni terminolojilere başvurduğu değerlendirilmiştir. 


\title{
EXTENDED ABSTRACT
}

\section{Analysis of the Education and Culture Programs of Milli Gorus Parties}

\author{
* \\ Yusuf Yalaniz - Beyhan Zabun \\ Economic and Social Researches Center, Gazi University
}

The transition to a multiparty political life in Turkey and the sociological changes experienced after 1950 caused a change in the perception of politics and, along with it, caused the social structure to become active. The clarification of the multi-party political system, an increase in society's effectiveness in politics, and the constitution prepared after the 1960 coup have developed a new understanding of civil society. Milli Gorus Movement, especially this civic mobility and the change in religious-political understanding, with the "Movement of Independents" in 1969, has taken place in Turkey's political history. Later, Milli Gorus parties became coalition partners three times as a result of their historical flow, and once took the task of forming a government. Although Turkey's political life as a coalition party did not stay in power for a long time, the understanding that Milli Gorus parties bring to politics has found a unique response in society and politics.

The leader of the movement, Prof. Dr Necmettin Erbakan, with the idiosyncratic character and style of politics, had brought a distinct aspect to Turkey's politics. The most important factors that led Erbakan to the leadership of the movement and made him an effective actor in politics was his education level, Islamic background, academic and bureaucratic career, leadership qualities, national attitude in evaluating country issues, Islamic collective attitude, and world view (Tekin, 2017, s.240-243).

Although the Milli Nizam Party had a high-level structure and a modern educated team's appearance, it had been closed. Later, Refah Party and Fazilet Party were banned by the Constitutional Court, notably with the claim that they were the focus of religious-political understanding and anti-secular actions. Although the Milli Selamet Party was shut down with the September $12^{\text {th }}$ Military Coup, the party leaders were accused by military courts for putting religious discourses to the fore. 
When the party programs, election declarations, coalition protocols, assembly speeches, press statements, and other party official publications are examined in the line from Milli Nizam Party to the Saadet Party, the religious style, grounding, and background are explicitly observed. Hence, the majority of works with the theme of "Milli Gorus" in different fields focused on the contexts of "the phenomenon of religion" and the relationship between religion and politics.

Similar qualities were also analyzed in this study, in which the educational and cultural programs of the Milli Gorus parties were evaluated. However, the centre of gravity of the context is related in a broader literature that corresponds to the "party-society-political" axis rather than a centre where the relationship between religion and politics is constantly engaged.

In this article, the Milli Gorus parties' approaches to the fields of education and culture have been evaluated. According to the analysis, it has been determined that every Milli Gorus party, after closing, reopened in different forms, changed its discourse according to its conjuncture, and periodic statements regarding the areas where opinions were expressed. In light of all these evaluations, the main centre of the study constitutes the cyclic evaluation of the Milli Gorus parties' educational and cultural programs.

The political stance of the Milli Nizam Party, the first political party of the Milli Gorus Movement, constitutes the "milli" and "non-milli" distinction. Milli Nizam Party aims to create a "religious person" type/profile with education. The reflection of this understanding at the macro level is the project of forming a "moral order". Education was also the subject that Milli Nizam Party focused the most on the party program's narrative, and the statements made about this area are the most assumed factors in the party's closure.

The slogan "First, to be Morality and Live by Thinking of the Hereafter." constitutes the basis of the education understanding of Milli Selamet Party. The main goal desired to be achieved through national education is stated as "the transmission of milli morale and thinking of the hereafter traits to the new generations." Milli Selamet Party, within these objectives, has set more clear and concrete goals in its program than Milli Nizam Party. Also, regarding culture, the most important project of the period was the cultural cooperation and organization thought to be established between Islamic countries. This is also an indication that an ummah tradition is followed. 
Compared to other Milli Gorus parties, Refah Party had made the most systematic entrance in the field of education. Refah Party, within the scope of the "Just Order" project, had tried to justify the "Knowledge / Moral Order". However, due to this project's emphasis on "ideal order", it's handling of the issues in a supra-political style did not make it understandable in terms of concrete, current and political agenda. Also concerning culture, the most notable events in this period were the studies conducted at the level of the Ministry of Culture within D-8, and the negative opinions had been expressed in the fields of opera and ballet in the assembly. These facts (clearly) reveal Refah Party's culture portfolio and national culture perception.

Again, in this period, the "February 28 Post-modern Coup" and the proposal made by the General Staff in the National Security Council subject to the intervention were predominantly based on education and culture, which shows the Milli Gorus parties can provide both political and social impact.

FP has put forward a different political style in the National Vision tradition. In this period, religious elements were minimized in terms of the parties and political style had shaped over universal values. Also, regarding culture, mentioning the importance and development of literature, folklore, painting, music, cinema, and theatre shows the dimensions of change.

During the Saadet Party period, education and culture were evaluated in two different stages. In the first stage, the Refah Party era's political attitude returned again, which continues until June 12, 2011 elections. The second stage is the perception of a party's vision of changing in the face of political developments in Turkey. In this period, it was determined that the Saadet Party in the field of education and culture tried to put forward based more on society perspective that appeals to a broader audience rather than focusing on specific segments.

According to Tekin (2017, p. 224), in the main axis of the changes in the Milli Gorus parties was the pressures faced by the political and social fields in Turkey. Therefore, considering the reasons for the closure of the parties, it is evaluated that they resort to new formal terminologies to eliminate a certain political crunch, to overcome the arguments focused on the parties, to protect the legitimacy ground and to convey their views to the society. 


\section{Kaynakça / References}

Akpınar, N. (2009). Maddi-maneoi kalkınma: Necmettin Erbakan örneği. Yüksek Lisans Tezi, Marmara Üniversitesi Sosyal Bilimler Enstitüsü, İstanbul.

Bakacak, Ç. (2010). Türkiye'de İslam'ın siyasallaşma serüveni: Milli Görüş ve partileri. Doğudan Dergisi, 15, 54-60.

Bellamy, R. (2012). Democracy, compromise and the representation paradox: Coalition government and political integrity. Government and Opposition, 47(3), 441-465.

Bozan, İ. (2007). Devlet ile toplum arasinda "bir okul: imam hatip liseleri. . . bir kurum: Diyanet İşleri Başkanlığı... İstanbul: TESEV Yayınları

Bulaç, A. (2009). Göçün ve kentin siyaseti (MNP'den SP'ye Milli Görüş partileri). İstanbul: Çıra Yayınları.

Çaha, Ö. (2004). Ana temalarıyla 1980 sonrası İslami uyanış. Y. Aktay (Ed.), Modern Türkiye'de Siyasi Düşünce, İslamcllk içinde (s. 476-492). İstanbul: İletişim Yayınları.

Çakır, R. (2004). Milli Görüş Hareketi. Y. Aktay (Ed.), Modern Türkiye'de Siyasi Düşünce, İslamcllk içinde (s. 544-549). İstanbul: İletişim Yayınları.

Emre, S. A. (2015). Siyasette 35 yıl (Cilt 1, 2 \& 3). Ankara: MGV Yayınları.

Erbakan, N. (1973). Milli Görüş ve 3. beş yıllık plan. Ankara: Furkan Yayınevi.

Erbakan, N. (1975). Maarif, iç bakış, herkese refah, anahtar ve Milli Görüş-temel görüş. Ankara: Güneş Matbaacilik.

Erbakan, N. (1991). Adil ekonomik düzen. Ankara: Semih Ofset Matbaacllk.

Fazilet Partisi (1998a). Kalkmma programı "öncü Türkiye için el ele.

Fazilet Partisi (1998b). Türkiye'nin öncelikleri ve temel görüşlerimiz. Ankara: Semih Ofset Yayinclik.

Fazilet Partisi (1999). Gün ışı̆̆ında Türkiye "18 nisan 1999 seçim beyannamesi".

Kazan, Ş. (2003). Refah gerçeği (Cilt 3). Ankara: Keşif Yayınları.

Milli Nizam Partisi (1970a). Milli Nizam Partisi kuruluş beyannamesi. Ankara: Nüve Matbaasi.

Milli Nizam Partisi (1970b). Milli Nizam Partisi programı.

Milli Nizam Partisi (1971). Milli Nizam Partisi 1. Büyük Kongresi.

Milli Selamet Partisi (1973). Milli Selamet Partisi seçim beyannamesi. İstanbul: Fatih Yayınevi.

Milli Selamet Partisi (1977). Inanç ve hamle. Ankara: Gaye Matbaası.

Milli Selamet Partisi (1978). Milli Selamet Partisi 4. büyükk kongresi. Ankara: Elif Matbaacllı.

Refah Partisi (1990). Refah Partisi 3. olağan büyük kongresi, genel başkan Prof. Dr. Necmettin Erbakan'ın açış konuşması.

Refah Partisi (1991). 20 Ekim 1991 genel seçimi Refah Partisi seçim beyannamesi.

Refah Partisi (1997). İktidarda 1 yıl (RP-DYP koalisyonu icraatlar).

Saadet Partisi (2001). Saadet Partisi programı. 
Saadet Partisi (2002). Acil onarm ve atılim programı: Saadet Partisi seçim beyannamesi 3 kastm 2002".

Saadet Partisi (2003). Prof. Dr. Necmettin Erbakan, Saadet Partisi 1. Olağan Büyükk Kongre Konuşmast.

Saadet Partisi (2004). AB Türkiye ilerleme raporu'nun gerçek yüzü ve gizli tuzaklar.

Saadet Partisi (2011). Geliyoruz! Bolluk, bereket, refah geliyor! "2011 seçim beyannamesi".

Saadet Partisi (2018). Türkiye Vizyonu: değişim, onarım, yatırım, atılım "seçim beyannamesi 24 haziran 2018 genel seçimleri".

Sarıbay, A. Y. (1985). Türkiye'de modernleşme din ve parti politikası: Milli Selamet Partisi örnek olayı. İstanbul: Alan Yayıncilik.

Sarıbay, A. Y. (2004). Milli Nizam Partisi'nin kuruluşu ve programının içeriği. Y. Aktay (Ed.), Modern Türkiye'de Siyasi Düşünce, İslamcllk içinde (s. 576-590). İstanbul: İetişim Yayınları.

Tahhan, M. (2007). Turkiya elleti araft, mines'suldan ila Necmeddin Erbakan 1842-2006. Kuwait: Merkez el-Diraset el-İslamiyye Yayınları.

TBMM (2012). Türk parlamento tarihi. H. E. Bağce (Dizi Ed.), TBMM - XV. Dönem (19731977) Cilt 1-3. Ankara: TBMM Kültür, Sanat ve Yayın Kurulu Yayınları.

TBMM(2015). Koalisyon hükümetleri, koalisyon protokolleri, hükümet programlarn ve genel kurul görüşmeleri. İ. Neziroğlu ve T. Yilmaz (Ed.): Cilt 1-3. Ankara: Türkiye Büyük Millet Meclisi Başkanlığı Yayınları.

TBMM Tutanak Dergisi (1996). Dönem: 20, Cilt: 17, Birleşim 37, s. 272-274.

TBMM Tutanak Dergisi (1997). Dönem: 20, Cilt: 21, Birleşim 60, s. 218-219.

Tekin, A. R. (2017). Türk dış politikasında Prof. Dr. Necmettin Erbakan: Kimlik, siyaset ve diş politika. Turkish Studies, International Periodical for the Languages, Literature and History of Turkish or Turkic, 12(8), 211-246.

Toprak, B. (2000). Türkiye'de dinin denetim işlevi. Türkiye'de Politik Değişim ve Modernleşme. Der. E. Kalaycioğlu, A. Y. Sarıbay. İstanbul: Alfa Basım Yayın.

Wendt, F. (2013). Peace beyond compromise. Critical Review of International Social and Political Philosophy, 16(4), 573-593.

Yavuz, H. (2004). Milli Görüş Hareketi: muhalif ve modernist gelenek. Y. Aktay(Ed.), Modern Türkiye'de Siyasi Düşünce, İslamcllk içinde (s. 591-603). İstanbul: İletişim Yayinları.

Zengin, B. (1995). Özgürleşerek birlikte yaşamak. İstanbul: Birleşik Yayıncllı. 


\section{Kaynakça Bilgisi / Citation Information}

Yalanız, Y. ve Zabun, B. (2021). Milli Görüş partilerinin eğitim ve kültür programlarının değerlendirilmesi. OPUS-Uluslararası Toplum Araştırmaları Dergisi, 17(33), 750-778. DOI: 10.26466/opus.812741 